\title{
Choosing between NSAID and arnica for topical treatment of hand osteoarthritis in a randomised, double-blind study
}

\author{
Widrig, Reto ; Suter, Andy ; Saller, Reinhard ; Melzer, Jörg
}

\begin{abstract}
The use of topical preparations for symptom relief is common in osteoarthritis. The effects of ibuprofen (5\%) and arnica (50g tincture/100g, DER 1:20), as gel preparations in patients with radiologically confirmed and symptomatically active osteoarthritis of interphalangeal joints of hands, were evaluated in a randomised, double-blind study in 204 patients, to ascertain differences in pain relief and hand function after 21days' treatment. Diagnosis was according to established criteria; primary endpoints were pain intensity and hand function; statistical design was as per current regulatory guidelines for testing topical preparations. There were no differences between the two groups in pain and hand function improvements, or in any secondary end points evaluated. Adverse events were reported by six patients (6.1\%) on ibuprofen and by five patients $(4.8 \%)$ on arnica. Our results confirm that this preparation of arnica is not inferior to ibuprofen when treating osteoarthritis of hands
\end{abstract}

DOI: https://doi.org/10.1007/s00296-007-0304-y

Posted at the Zurich Open Repository and Archive, University of Zurich

ZORA URL: https://doi.org/10.5167/uzh-155950

Journal Article

Published Version

Originally published at:

Widrig, Reto; Suter, Andy; Saller, Reinhard; Melzer, Jörg (2007). Choosing between NSAID and arnica for topical treatment of hand osteoarthritis in a randomised, double-blind study. Rheumatology international, 27(6):585-591.

DOI: https://doi.org/10.1007/s00296-007-0304-y 


\title{
Choosing between NSAID and arnica for topical treatment of hand osteoarthritis in a randomised, double-blind study
}

\author{
Reto Widrig • Andy Suter • Reinhard Saller • \\ Jörg Melzer
}

Received: 12 October 2006 / Accepted: 26 December 2006 / Published online: 22 February 2007

(C) Springer-Verlag 2007

\begin{abstract}
The use of topical preparations for symptom relief is common in osteoarthritis. The effects of ibuprofen (5\%) and arnica (50 g tincture/100 g, DER $1: 20)$, as gel preparations in patients with radiologically confirmed and symptomatically active osteoarthritis of interphalangeal joints of hands, were evaluated in a randomised, double-blind study in 204 patients, to ascertain differences in pain relief and hand function after 21 days' treatment. Diagnosis was according to established criteria; primary endpoints were pain intensity and hand function; statistical design was as per current regulatory guidelines for testing topical preparations. There were no differences between the two groups in pain and hand function improvements, or in any secondary end points evaluated. Adverse events were reported by six patients $(6.1 \%)$ on ibuprofen and by five patients $(4.8 \%)$ on arnica. Our results confirm that this preparation of arnica is not inferior to ibuprofen when treating osteoarthritis of hands.
\end{abstract}

Keywords Osteoarthritis - Ibuprofen gel · Arnica gel · Randomised trial $\cdot$ Gel treatment

R. Widrig

Rheumatology Clinic, 9004 St Gallen, Switzerland

\section{A. Suter}

Bioforce AG, 9325 Roggwil, Switzerland

R. Saller · J. Melzer $(\bowtie)$

Department of Internal Medicine, Institute of Complementary Medicine,

University Hospital Zurich, Raemistrasse 100,

CH-8091 Zurich, Switzerland

e-mail: joerg.melzer@usz.ch

\section{Introduction}

Osteoarthritis (OA) is one of the most common joint disorders affecting mature adults and the elderly, in whom the prevalence of hand symptoms ranges from $13 \%$ (men) to $26 \%$ (women), according to the Framingham Study [1]. The commonest affected joints are the distal interphalangeal (DIP) followed by proximal interphalangeal (PIP) and the metacarpal-phalangeal (MCP) joints, with gradual cartilage destruction associated with development of nodule-like swellings on both sides of the joints (Heberden and Bouchard nodes for DIP and PIP, respectively). Swelling and redness are usually mild but may be accompanied by severe pain and increasing functional impairment [2].

Current treatment is essentially supportive and symptomatic [3], as there is no available therapy to reverse or halt the natural progression of OA. Analgesics and non-steroidal anti-inflammatory drugs (NSAIDs) such as ibuprofen and diclofenac remain the mainstay of drug treatment. Ibuprofen, in use for over forty years, has been shown to relieve OA symptoms effectively [4] and intra-articular steroids and hyaluronic acid derivatives are also used, whilst physiotherapy and other supportive care have been shown to improve function [3]. Topical use of NSAIDs reduces systemic adverse effects, particularly on the gastrointestinal (GI) tract [5] and a meta-analysis of 86 placebo controlled studies (10,160 patients) confirmed the benefits of various topical agents [6], while ibuprofen gel $5 \%$ has been shown to be effective in musculoskeletal injuries [7, 8], tendonitis [9], general osteoarthritis [10] and osteoarthritis of the knee and finger joints $[11,12]$.

Drug penetration and bioavailability of ibuprofen gel $5 \%$ in muscle and connective tissue beneath the 
application site are in the same order of magnitude as after oral administration [13,14].

Topical phytotherapy preparations such as extracts of willow bark, devil's claw, capsicum and arnica are also frequently used [15]. Arnica montana $L$ (other names are: arnica, mountain tobacco, medicinal leopard's bane; mountain alkanet) has been used as a topical agent since at least the sixteenth century [16], and nowadays most frequently for the treatment of contusions and sprains, or for symptomatic relief in OA [17].

We stipulated three pre-conditions for choosing the arnica preparation amongst the numerous available. Firstly, the preparation had to have published evidence from preclinical studies of some anti-inflammatory action, secondly the preparation had to have published evidence of skin penetration and, thirdly it had to be available as gel and should be as similar as possible to ibuprofen gel, to ensure blindness during the study. Our chosen preparation has shown evidence of complete inhibition of the transcription factor NF-kappaB by arnica constituents (sesquiterpene lactone helenalin, $11 \alpha, 13$-dihydrohelenalin and its ester) [18], which is similar to the effects of glucocorticoids on inflammatory cascade [19], as well as skin penetration [20]. In appearance, arnica gel was indistinguishable from ibuprofen.

\section{Materials and methods}

Patient selection and blinding

We enrolled patients from 20 clinics (12 general practices, 6 rheumatology clinics, 2 general medicine) in three Swiss cantons (Zurich, St Gallen and Aargau) between May 2003 and March 2004. A total of 204 patients were enrolled, of whom 198 were included in the intention-to-treat (ITT) analysis and a further 24 patients were excluded from the per protocol (PP) analysis (Table 1). Diagnosis was according to established criteria [21]. Patient selection was conducted according to the Osteoarthritis Research Society International (OARSI) guidelines [22] and their recommendations for studying polyarthritis of finger joints, and the European Medicines Agency (EMEA) guidelines on choice of controlled studies and statistical design regarding gel evaluations [23, 24]. The study was conducted according to Good Clinical Practice guidelines and the Declaration of Helsinki, and approved by the relevant Ethics Committees and Swiss regulatory authorities.

Patients were initially screened and, if considered eligible and consented, they were randomised to one of the two treatment groups (ibuprofen or arnica). The protocol selection criteria are summarised in Table 2 . Before being dispensed treatment, patients were fully medically evaluated. Both treatments were to be used in identical dispensing doses of gel (4 cm strip), gently rubbed over the affected joints thrice-daily for 3 weeks, and were asked not to wash hands for one hour after application. Patients were dispensed a preset number of paracetamol tablets $(20 \times 500 \mathrm{mg}$ tablets $)$ as "escape treatment" (not allowed within $24 \mathrm{~h}$ prior to the final evaluation) and asked to return any unused tablets at the end of the treatment course. For patients on long-term low-dose aspirin for cardiovascular conditions, $325 \mathrm{mg}$ daily maximum was allowed.
Table 1 Disposition, demographics and status of patients in the study

\footnotetext{
No statistical difference between groups in any demographic or status parameters at baseline

${ }^{\text {a }}$ Mean value of 1 none, 2 slight, 3 moderate, 4 severe, 5 extreme morning stiffness

b Mean value of 1 none, 2 up to $2 \mathrm{~min}, 3$ up to $5 \mathrm{~min}, 4$ up to $10 \mathrm{~min}, 5$ more than $10 \mathrm{~min}$
}

\begin{tabular}{|c|c|c|c|c|}
\hline \multirow[b]{2}{*}{ Randomized $(n)$} & \multicolumn{2}{|c|}{ Ibuprofen gel } & \multicolumn{2}{|c|}{ Arnica gel } \\
\hline & 99 & - & 105 & - \\
\hline Excluded at baseline visit $(n)$ & 1 & - & 5 & - \\
\hline ITT Population $(n, \%)$ & 98 & 100.0 & 100 & 100.0 \\
\hline Treatment duration $<18$ or $>26$ days $(n, \%)$ & 6 & 5.9 & 3 & 3.0 \\
\hline Use of (excluded) analgesics $(n, \%)$ & 2 & 2.0 & 2 & 2.0 \\
\hline No per protocol radiological evidence $(n, \%)$ & 2 & 2.0 & 2 & 2.0 \\
\hline Hand function $<5$ (HAI) or Pain $<4$ (VAS) $(n, \%)$ & 2 & 2.0 & 2 & 2.0 \\
\hline Early intolerance of gel $(n, \%)$ & 1 & 1.0 & 2 & 2.0 \\
\hline Total exclusions $(n, \%)$ & 13 & 12.7 & 11 & 11.0 \\
\hline Per protocol population $(n, \%)$ & 85 & 83.3 & 89 & 89.0 \\
\hline Age (years; mean, SD) & 64 & 11.4 & 64 & 12.0 \\
\hline Females ( $n, \%$ PP population) & 72 & 61.2 & 75 & 66.8 \\
\hline Weight (kg; mean, SD) & 71 & 13.3 & 70 & 13.4 \\
\hline Affected fingers $(n ;$ mean, SD) & 7 & 2.1 & 7 & 2.0 \\
\hline Affected joints $(n ;$ mean, SD) & 11 & 4.1 & 11 & 5.0 \\
\hline Hand algofunctional index (mean, SD) & 12 & 3.3 & 11 & 4.0 \\
\hline Pain intensity (VAS; mean, SD) & 68 & 14.2 & 67 & 14.4 \\
\hline Painful joints $(n ;$ mean, SD) & 8 & 4.6 & 9 & 4.9 \\
\hline Morning stiffness intensity ${ }^{a}($ mean, SD) & 3 & 0.9 & 3 & 0.8 \\
\hline Morning stiffness duration ${ }^{\mathrm{b}}$ (mean, SD) & 4 & 1.1 & 4 & 1.0 \\
\hline
\end{tabular}


Table 2 Patient selection

Inclusion criteria

Patients of either gender

Age between 18 and 88 years, inclusive

Osteoarthritis diagnosis according to ARC criteria (modified by Altman) [21]

(a): pain or stiffness in the hands or fingers on most days during the previous month

(b) hard tissue enlargement in $\geq 2$ of ten joints (DIP and PIP joints II/III as well as

both carpal-metacarpal joints)

(c) less than two swollen MCP joints

(d) $\geq 1$ DIP joint with hard tissue enlargement or $\geq 1$ of the joints referred to under (b)

In addition, the following criteria applied for the worst affected hand

Pain intensity of on the Visual Analogue Scale (VAS 0-100 mm) of at least $40 \mathrm{~mm}$ in the finger

joint with the worst possible spontaneous pain in the previous $24 \mathrm{~h}$

At least 5 points, measured on the Hand Algofunctional Index (HAI)

Radiological confirmation of osteoarthritis in $\geq 2$ joints with radiographs $\leq 3$ months old and $\geq 1$

painful joint confirmed radiologically

Discontinuation of all NSAIDs (topical and systemic) $>10$ days prior to entry

Discontinuation of all analgesics $>3$ days prior to entry

Written Informed consent

Exclusion criteria

Secondary osteoarthritis (due to causes other than solely degenerative joint disease)

Trauma to the hand or arm in the previous 2 months

Residual pain following fracture, dislocation or operation

Pain and stiffness due to tissue scarring

Tendinitis

Carpal tunnel or other nerve compression syndromes

Serious conditions, such as cancer, uncontrolled hypertension or heart failure

Systemic or intra-articular corticosteroids in the previous month and during study

Damaged skin or serious skin disorders affecting hands

Allergy to Asteraceae

Intolerance to paracetamol

Ibuprofen Gel 5\% (Optifen ${ }^{\circledR}$ Gel) was supplied by Spirig Pharma Ltd, and Arnica Gel (A. Vogel Arnica $\mathrm{Gel}^{\circledR}$; Arnica montana fresh herbal tincture $50 \mathrm{~g} / 100 \mathrm{~g}$ gel; drug-to-extract ratio (DER) of the tincture 1:20) was supplied by Bioforce AG.

\section{Statistics}

The aim of the study was to evaluate the efficacy and tolerability of arnica gel compared to ibuprofen gel 5\% in the treatment of $\mathrm{OA}$ of the fingers using the approach (non-inferiority) suggested by current guidance on comparisons of gel preparations [23, 24]. Randomisation codes were computer-generated in blocks of four (RanCode, Version 3.6, IDV-Gauting, Germany). Double-blindness was assured by identical packaging (100 $\mathrm{ml}$ tubes), as well as gel appearance and consistency. There was a slight difference in odour for the first $30 \mathrm{~s}$ after application, after which both were odourless. We considered this of no practical consequence for blindness because patients only received one of the treatments, so they were not aware of the comparator.

The primary efficacy parameters were: (a) reduction in pain, recorded as the most intense in the previous $24 \mathrm{~h}$, in the worst affected finger, on VAS $(100 \mathrm{~mm})$ by the patient and; (b) functional capacity of the hand using the validated HAI assessment (Table 3) [25]. The secondary parameters were: (a) number of painful joints (DIPs, PIPs and MCPs) in both hands; (b) intensity of morning stiffness in the worst affected hand; (c) duration of morning stiffness in the worst affected hand; (d) analgesic consumption; (e) patients' and doctors' global evaluation of efficacy; (f) patients' acceptance of the gel treatment. Safety was to be evaluated by adverse event monitoring.

Non-inferiority (arnica relative to ibuprofen) was set as the difference being not greater than $12 \%$ in each of

Table 3 Hand algofunctional index

1. Are you able to turn a key in a lock?

2. Are you able to cut meat with a knife?

3. Are you able to cut cloth or paper with a pair of scissors?

4. Are you able to lift a full bottle with one hand?

5. Are you able to clench a fist?

6. Are you able to tie a knot?

7a. For women: Are you able to sew?

7b. For men: Are you able to use a screwdriver?

8. Are you able to fasten buttons?

9. Are you able to write for a long period of time?

10. Would you accept a handshake without reluctance?

Scores: 0 possible without difficulty; 1 possible with slight difficulty; 2 possible with significant difficulty; 3 impossible 
the two main assessment tools, which corresponds to 3.6 points on HAI (for hand function) and $12 \mathrm{~mm}$ on the VAS (for pain), hence a standardised difference (effect size) of 0.66. A standard deviation of 5.5 was derived from the validation data of HAI [25]. The Mann-Whitney statistic $P(X<Y)$ was used as a measure of relevance for the difference, hence: $P(X<Y)<0.5$ (inferiority); $P(X<Y)=0.5$ (no difference); $P(X<Y)>0.5$ (superiority). The Mann-Whitney statistics (for an effect size of 0.66 ) corresponds to $P(X<Y)=0.322$.

Non-inferiority of arnica was to be formally shown when the left margin of the one-sided $\alpha$-confidence limit of the Mann-Whitney statistic was greater than 0.322. In a first step, H01 was tested (arnica < ibuprofen for combined pain and hand function). If the left margin of the one-sided $\alpha$-confidence limit were greater than 0.322 , then hypotheses $\mathrm{H} 02$ and H03 (arnica < ibuprofen for pain and hand function, respectively) were tested, maintaining the global level of significance (closed test principle).

Sample size calculation was based on an assumption that the difference between the two treatments would be not more than -1 point on HAI. Thus, with a standard deviation of 5.5 , a one-sided $t$-test with significance level of alpha $=0.024$ and $80 \%$ power gives a sample size of 73 patients per group to reject the null hypothesis (inferiority of arnica). Since the power of the Wilcoxon test is slightly inferior to that of $t$-test (for a normal distribution), a minimum of 80 assessable cases (per protocol) were required. An interim analysis was planned for possible adjustment of sample size after 60 patients were entered, for which the statistical tests were adjusted accordingly and the confidence interval was restricted to $95.2 \%$. No adjustments were required to the sample size during the interim analysis.

An ITT analysis was to be conducted similarly to the PP analysis but including all randomised patients who had used the gel at least once and who had a post-baseline value for comparison. The safety analysis was to be conducted in all patients who used treatment at least once.

\section{Results}

On entry, there were no differences between groups regarding any demographic or disease parameter (Table 1).

Pain intensity and hand function were similarly improved in both treatment groups, the differences being within the $95.2 \%$ confidence intervals and the inferiority thresholds (Table 4). The generalised Wil- coxon's test for the treatment difference was above the defined non-inferiority threshold of 0.322 . Thus, the first hypothesis that arnica is inferior to ibuprofen in terms of both target parameters (function and pain) was rejected and the two criteria could be tested for the one-sided level $\alpha=0.024$, which showed the left limit of the respective two-sided $95.2 \%$ confidence regions also greater than 0.322 for the two individual parameters, so the inferiority hypothesis was not proven for the two criteria. Results from the analysis of the ITT population were essentially identical to those of the PP population.

The results were also similar for both groups for all secondary parameters (Table 4$)$. Mean $( \pm$ SD) paracetamol consumption as "escape treatment" was $11.3 \pm 7.2$ and $11.2 \pm 6.8$ tablets (ibuprofen and arnica, respectively) during the 3 weeks.

Global efficacy evaluation by physicians was very good or good in 56.5\% (ibuprofen) and 64.0\% (arnica), while patients rated efficacy very good or good in $58.8 \%$ (ibuprofen) and $64.1 \%$ (arnica) of cases (Table 5). Patients' acceptance of the gel treatment was 76.5 and $78.7 \%$ (very satisfied or satisfied; ibuprofen and arnica, respectively) (Fig. 1).

Both treatments were well tolerated by patients, with 6.1 and $4.8 \%$ of patients on ibuprofen and arnica, respectively, reporting a treatment-related adverse event. The skin was the main target organ for events (Table 6). There was one serious event (back trauma due to fall), not related to treatment (arnica).

\section{Discussion}

Although a multitude of topical gel preparations for OA of peripheral joints are used by patients and prescribed by doctors, we set out to evaluate whether there was a noticeable difference between a commonly used synthetic NSAID and a traditional phytotherapeutic, when tested by objective methods using validated assessment tools, and according to the perceptions of doctors and patients. Our results demonstrate that topical arnica gel is not inferior to ibuprofen gel, regarding hand functional capacity, pain intensity, number of painful joints, duration and severity of morning stiffness, or paracetamol consumption. Importantly, not only were improvements in all parameters similar, they were also clinically relevant. When blinded to treatment, neither patients nor doctors can distinguish between the effects of these two treatments.

There were some limitations in our study, but these were minor and did not affect the plausibility of the results. Firstly, although similar in every other way 
Table 4. Results

\begin{tabular}{|c|c|c|c|c|}
\hline \multirow[t]{2}{*}{ Main endpoints } & \multicolumn{2}{|l|}{ Pain (VAS) } & \multicolumn{2}{|c|}{ Hand function (HAI) } \\
\hline & $\begin{array}{l}\text { Ibuprofen gel } \\
(n=85)\end{array}$ & $\begin{array}{l}\text { Arnica gel } \\
(n=89)\end{array}$ & $\begin{array}{l}\text { Ibuprofen gel } \\
(n=85)\end{array}$ & $\begin{array}{l}\text { Arnica gel } \\
(n=89)\end{array}$ \\
\hline \multicolumn{5}{|l|}{ PP population } \\
\hline Day 0: mean (SD) & $68.0(14.2)$ & $66.9(14.4)$ & $12.1(3.3)$ & $11.3(4.0)$ \\
\hline Day 21: mean (SD) & $44.2(20.9)$ & $40.4(21.5)$ & $7.5(4.3)$ & $7.1(4.8)$ \\
\hline Difference: Day 0-Day 21: mean (SD) & $-23.9(23.3)$ & $-26.6(22.4)$ & $-4.6(3.1)$ & $-4.3(3.6)$ \\
\hline Difference: Ibuprofen-Arnica: mean (SD) & $3.4(20.8)$ & & $-0.2(3.4)$ & \\
\hline $95.2 \% \mathrm{CI}$ for difference & {$[-2.9 ;+9.7]$} & & {$[-1.3 ;+0.8]$} & \\
\hline Associated inferiority threshold & -12.0 & & -3.6 & \\
\hline Primary variable test* $P(X<Y)+0.5^{*} P(X=Y)$ & 0.5407 & & 0.4683 & \\
\hline $95.2 \% \mathrm{CI}$ & {$[0.455 ; 0.627]$} & & {$[0.382 ; 0.554]$} & \\
\hline Directional test* for Primary Variable & 0.5045 & & & \\
\hline For $95.2 \% \mathrm{CI}$ & {$[0.428 ; 0.581]$} & & & \\
\hline Secondary endpoints & Ibuprofen gel & Arnica gel & Difference & {$[95 \% \mathrm{CI}]$} \\
\hline \multirow{5}{*}{$\begin{array}{l}\text { Number of painful joints } \\
\text { Intensity of morning stiffness }{ }^{a} \\
\text { Duration of morning stiffness }\end{array}$} & $-2.5(3.2)$ & $-3.0(4.4)$ & 0.4 & {$[-0.6 ;+1.4]$} \\
\hline & $-1.0(0.8)$ & $-0.9(1.1)$ & -0.1 & {$[-0.1 ;+0.2]$} \\
\hline & $-0.8(1.1)$ & $-0.9(1.3)$ & 0.0 & {$[-0.3 ;+0.3]$} \\
\hline & \multicolumn{2}{|l|}{ Pain (VAS) } & \multicolumn{2}{|c|}{ Hand function (HAI) } \\
\hline & $\begin{array}{l}\text { Ibuprofen gel } \\
(n=98)\end{array}$ & $\begin{array}{l}\text { Arnica gel } \\
(n=100)\end{array}$ & $\begin{array}{l}\text { Ibuprofen gel } \\
(n=98)\end{array}$ & $\begin{array}{l}\text { Arnica gel } \\
(n=100)\end{array}$ \\
\hline \multicolumn{5}{|l|}{ ITT population } \\
\hline Difference: Day 0-day 21 (SD) & $-22.6(24.0)$ & $-25.1(22.5)$ & $-4.2(3.6)$ & $-4.1(3.6)$ \\
\hline Difference: Ibuprofen-Arnica (SD) & $2.5(21.3)$ & & $-0.1(3.6)$ & \\
\hline $95.2 \%$ CI for difference & {$[-3.1 ; 9.0]$} & & {$[-1.1 ; 1.0]$} & \\
\hline Primary variable test* $P(X<Y)+0.5^{*} P(X=Y)$ & 0.5288 & & 0.4741 & \\
\hline $95.2 \% \mathrm{CI}$ & {$[0.448 ; 0.610]$} & & {$[0.394 ; 0.555]$} & \\
\hline Directional test* for Primary variable & 0.5015 & & & \\
\hline For $95.2 \%$ CI & {$[0.429 ; 0.574]$} & & & \\
\hline
\end{tabular}

$P P$ Per protoco, ITT intention to treat, $H A I$ hand algofunctional index, $V A S$ visual analogue scale

${ }^{\text {a }}$ Mean value of 1 none, 2 slight, 3 moderate, 4 severe, 5 extreme morning stiffness

b Mean value of 1 none, 2 up to $2 \mathrm{~min}, 3$ up to $5 \mathrm{~min}, 4$ up to $10 \mathrm{~min}, 5$ more than $10 \mathrm{~min}$

(packaging, consistency, appearance, physical properties), blinding of the gels could be argued to have been sub-optimal because they emanated slightly different odours during the first $30 \mathrm{~s}$ of application. We feel this cannot have had a major influence in the results, because patients were only given one of the treatments and they were to be used at home. Should we have used a cross-over design (where each individual would be exposed to both gels), this might have had an influence on results. Secondly, despite our best efforts, we lost six patients from follow up for the ITT analysis. One has to consider that patients with chronic, non-life threatening conditions have slightly lower attendance compliance than those with serious illnesses. However, this was a very small number relative to the overall sample $(n=204)$ and it is highly unlikely that the ITT results would have changed in substance, if their postbaseline data were obtainable.
Consumption of paracetamol was strictly controlled and comparable in both groups. Yet, we were cautious to ensure even the "escape treatment" was discontinued $24 \mathrm{~h}$ before the final evaluation, to prevent an analgesic carry-over effect.

A review of topical NSAIDs indicated some superiority relative to placebo, particularly in soft tissue disorders, as well as equivalent efficacy when compared with some orally administered NSAIDs, although the literature was not very robust. The safety profile was acceptable (2\% self-limiting skin events). The cost-benefit analysis showed an initial higher cost for topical treatments but also an overall benefit [26].

Two meta-analysis of randomised trials with topical application of NSAIDs, one in osteoarthritis and rheumatoid [5] and one of osteoarthritis [27] showed superiority to placebo in pain reduction with short-term 
Table 5 Patients' and physicians' evaluations

\begin{tabular}{|c|c|c|}
\hline & $\begin{array}{l}\text { Ibuprofen gel } \\
(n=85)\end{array}$ & $\begin{array}{l}\text { Arnica gel } \\
(n=89)\end{array}$ \\
\hline & $n(\%)$ & $n(\%)$ \\
\hline \multicolumn{3}{|c|}{ Patients' evaluation of efficacy ${ }^{a}$} \\
\hline Very good efficacy & $21(24.7)$ & $27(30.3)$ \\
\hline Good efficacy & $29(34.1)$ & $30(33.7)$ \\
\hline Minor efficacy & $25(29.4)$ & $23(25.8)$ \\
\hline Unchanged condition & $10(11.8)$ & $9(10.1)$ \\
\hline \multicolumn{3}{|c|}{ Patients' acceptance of topical treatment } \\
\hline Very satisfied & $23(27.1)$ & $33(37.1)$ \\
\hline Satisfied & $42(49.4)$ & $37(41.6)$ \\
\hline Dissatisfied & $19(22.4)$ & $17(19.1)$ \\
\hline Very dissatisfied & $1(1.2)$ & $2(2.2)$ \\
\hline \multicolumn{3}{|c|}{ Doctors' evaluation of efficacy ${ }^{\mathrm{a}}$} \\
\hline Not assessable & $0(0.0)$ & $1(1.1)$ \\
\hline Very good efficacy & $23(27.1)$ & $27(30.3)$ \\
\hline Good efficacy & $25(29.4)$ & $30(33.7)$ \\
\hline Minor efficacy & $27(31.8)$ & $21(23.6)$ \\
\hline Unchanged condition & $10(11.8)$ & $10(11.2)$ \\
\hline
\end{tabular}

Good = significant improvement, partial symptoms remission;Minor $=$ slight improvement, requires other treatments

${ }^{\mathrm{a}}$ Very good $=$ complete or almost complete remission of all symptoms

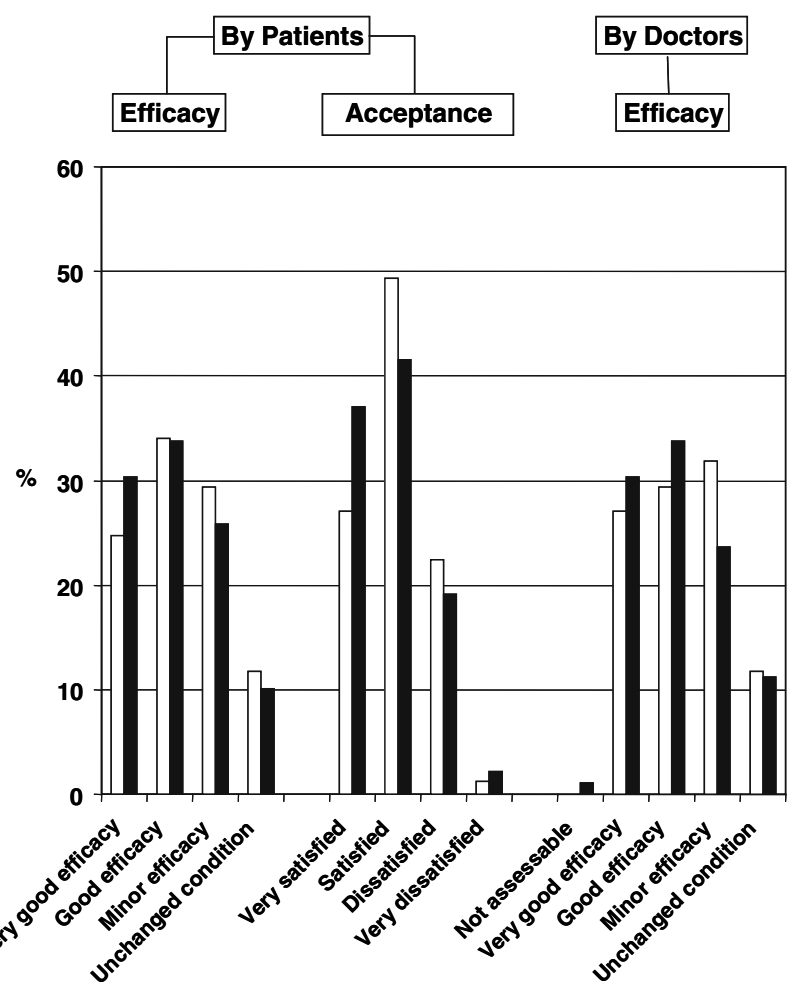

$\square$ Ibuprofen Gel $\square$ Arnica Gel

Fig. 1 Treatment perceptions by patients and doctors

(1-2 weeks) treatment. Topical NSAIDs are now recommended in osteoarthritis to reduce risk of adverse events associated systemic administration and to target
Table 6 Safety Results

\begin{tabular}{|c|c|c|}
\hline & $\begin{array}{l}\text { Ibuprofen } \\
\text { gel }(n=99)\end{array}$ & $\begin{array}{l}\text { Arnica } \\
\text { gel }(n=105)\end{array}$ \\
\hline & $n(\%)$ & $n(\%)$ \\
\hline $\begin{array}{l}\text { Patients with any } \\
\text { adverse event }\end{array}$ & $8(8.1)$ & $14(13.3)$ \\
\hline $\begin{array}{l}\text { Patients with treatment-related } \\
\text { events }^{\mathrm{a}}\end{array}$ & $6(6.1)$ & $5(4.8)$ \\
\hline Patients with serious events ${ }^{\mathrm{b}}$ & - & $1(1.0)$ \\
\hline Number of events & $9(9.1)$ & $15(14.3)$ \\
\hline $\begin{array}{l}\text { Number of treatment-related } \\
\text { events }\end{array}$ & $7(7.1)$ & $5(4.8)$ \\
\hline \multicolumn{3}{|l|}{ All events' List } \\
\hline \multicolumn{3}{|l|}{ Skin and Hand } \\
\hline Skin irritation/itching (hands) & 3 & 3 \\
\hline Increased finger pain & 2 & 2 \\
\hline Reddening & 1 & 1 \\
\hline Scaly skin & 1 & - \\
\hline Allergic eczema & - & 1 \\
\hline \multicolumn{3}{|l|}{ Others } \\
\hline Adnexitis & 1 & - \\
\hline Chest pain & 1 & - \\
\hline Bronchitis & - & 2 \\
\hline Back pain & - & 2 \\
\hline Chill & - & 1 \\
\hline Cystitis & - & 1 \\
\hline Rhinitis & - & 1 \\
\hline Vertigo & - & 1 \\
\hline Total & $9(9.1 \%)$ & $15(14.3 \%)$ \\
\hline
\end{tabular}

a Possibly, probably or definitely related to treatment

b One case of back pain due to fall causing withdrawal from treatment

local discomfort, particularly to control symptom flare up [28]. The analgesic properties of topical NSAIDs in particular, have been demonstrated with ibuprofen gel $5 \%$ (thrice-daily) versus oral ibuprofen ( $400 \mathrm{mg}$ thricedaily) [29]. Finally, our study investigated short-term use only, but this is in agreement with studies that suggest short-term, such as during flare ups, is the preferred setting for gel treatment [27].

While the skin route for medication is long established in dermatology, in the last few decades it has established itself in cardiology (nitrate patches) and it is gradually becoming common in rheumatology. In this regard, appropriate testing in methodologically strict studies is the only way to address, which amongst the wide variety of agents offer real benefit.

In summary, our results show that short-term use, up to three weeks, of arnica gel improves pain and function in hand OA, indistinguishably from ibuprofen gel. Similar effects are also observed with regard to number of painful joints, severity and duration of morning stiffness, as well as the perceived efficacy by patients and doctors. Topical application of arnica gel can be regarded as an alternative to ibuprofen gel when treating $\mathrm{OA}$ of the hand joints. 
Acknowledgments RS conceived the overall project plan. RW was the Principal Investigator. The following doctors treated and evaluated patients in the 20 study clinics: D. Kähler (Wil); R. Widrig (St Gallen); D. Geiger (Au); S. Bachmann (Valens); H. Martin (Gossau); M. Burla (Zürich); B. Kindler (Zürich); M. Senn (Zürich); U. Aufdenblatten (Zürich); H. Sajdl (Zürich); K. Grimm (Dietikon); E. Zeley-Zimonyi (Zürich); M. Steigbügel (Wald); U. Pachlatko (Ebmatingen); M. Tejero (Baden); B. Haldemann (Küttigen); H. Maurer (St Gallen); F. Akermann (Buchs); F. Jaggi (Zürich); A. Stevka (Zürich); H. Steinemann (St Gallen). Statistical analysis was conducted by DSH Statistical Services GmbH, Germany.

\section{References}

1. Zhang Y, Niu J, Kelly-Hayes M et al (2002) Prevalence of symptomatic hand osteoarthritis and its impact on functional status among the elderly: the Framingham Study. Am J Epidemiol 156:1021-1027

2. Hochberg MC, Vignon E, Maheu E (2000) Clinical assessment of hand OA. Osteoarthr Cartil 8(Suppl A):S38-S40

3. Stamm TA, Machold KP, Smolen JS et al (2002) Joint protection and home hand exercises improve hand function in patients with hand osteoarthritis: a randomized controlled trial. Arthritis Rheum 47:44-49

4. Moore N (2003) Forty years of ibuprofen use. Int J Clin Pract 135(Suppl Apr):28-31

5. Heyneman CA, Lawless-Liday C, Wall GC (2000) Oral versus topical NSAIDs in rheumatic diseases. Drugs 60:555-574

6. Moore RA, Tramèr MR, Carroll D et al (1998) Quantitative systematic review of topically applied non-steroidal antiinflammatory drugs. BMJ 316:333-338

7. Ramesh N, Steuber U (1983) Dolgit ${ }^{\circledR}$ cream in accident- and sports-related injuries in medical practice. Results of a double blind study. Therapiewoche 33:4563-4570

8. Machen J, Whitefield M (2002) Efficacy of a proprietary ibuprofen gel in soft tissue injuries: a randomised, double-blind, placebo-controlled study. Int J Clin Pract 56:102-106

9. Dreiser RL (1988) Clinical trial of efficacy and tolerability of topical ibuprofen in the treatment of tendonitis. Le J Int Méd 119:15-31

10. Nasonova VA Muravyev IuV, Nasonov EL et al (1995) Local application of dolgit cream in patients with osteoarthritis: multicentre study of efficacy and tolerance. Ter Arkh 67:48-50

11. Guillaume M (1988) Clinical study on the efficacy and tolerability of percutaneous ibuprofen for the symptomatic treatment of arthrosis of small joints. Etude clinique de l'efficacité et de la tolérance de l'ibuprofène percutané dans le traitement symptomatique de l'arthrose des petites articulations. J Intern Med 2:1-4

12. Trnavsky K, Fischer M, Voegtle-Junkert U, Schreyger F (2004) Efficacy and safety of 5\% ibuprofen cream treatment in knee osteoarthritis. Results of a randomized, double-blind, placebo-controlled study. J Rheumatol 31:565-572

13. Dominkus M, Nicolakis M, Kotz R et al (1996) Comparison of tissue and plasma levels of ibuprofen after oral and topical administration. Arzneimittelforschung 46:1138-1143
14. Steen AE, Reeh PW, Geisslinger G et al (2004) Plasma levels after peroral and topical ibuprofen and effects upon low pH induced cutaneous and muscle pain. Eur J Pain 4:195209

15. Ernst E (2004) Musculoskeletal conditions and complementary/alternative medicine. Best Pract Res Clin Rheumatol 18:539-556

16. Mayer JG et al (2000) Arnica montana or Mountain Arnicaa cultural-historical essay and on the problems of writing such an essay. Arnica montana L., oder Bergwohlverleih Ein kulturhistorischer Essay - und über die Schwierigkeiten einen solchen $\mathrm{zu}$ verfassen. Zeitschrift für Phytotherapie 21:30-36

17. Knuesel O, Weber M, Suter A (2002) Arnica montana gel in osteoarthritis of the knee: an open, multicentre clinical trial. Adv Ther 19:209-218

18. Lyss G, Schmidt TJ, Merfort I et al (1997) Helenalin, an antiinflammatory sesquiterpene lactone from Arnica, selectively inhibits transcription factor NF-KappaB. Biol Chem 378:951961

19. De Bosscher K, Vanden Berghe W, Vermeulen L et al (2000) Glucocorticoids repress NF-kappaB-driven genes by disturbing the interaction of p65 with the basal transcription machinery, irrespective of coactivator levels in the cell. Proc Nat Acad Sci 97:3919-3924

20. Wagner S, Suter A, Merfort I (2004) Skin penetration studies of Arnica preparations and of their sesquiterpene lactones. Planta Med 70:897-903

21. Altman R, Alarcon G, Appelrouth D et al (1990) The American College of Rheumatology criteria for the classification and reporting of osteoarthritis of the hand. Arthritis Rheum 33:1601-1610

22. Lequesne MG, Maheu E (2000) Methodology of clinical trials in hand osteoarthritis: conventional and proposed tools. Osteoarthr Cartil 8(Suppl A):S64-S69

23. European Medicines Agency (EMEA) Guideline on the choice of non-inferiority margin. [Document locator: CPMP/ EWP/2158/99]. Available from: http://www.emea.eu.int/pdfs/ human/ewp/215899en.pdf (Accessed: 25.04.06)

24. European Medicines Agency (EMEA) Note for Guidance on Choice of Control Groups in Clinical Trials. (Document locator: CPMP/ICH/364/96). Available from: http://www.emea.eu. int/pdfs/human/ich/036496en.pdf (Accessed: 25.04.06)

25. Dreiser RL, Maheu E, Guillou GB et al (1995) Validation of an algofunctional index for osteoarthritis of the hand. Rev Rhum Engl Ed 62(6 Suppl 1):S43-S53

26. Vaile J, Davis P (1998) Topical NSAIDs for musculoskeletal conditions. A review of the literature. Drugs 56:783-799

27. Lin J, Zhand W, Jones A, Doherty M (2004) Efficacy of topical non-steroidal anti-inflammatory drugs in the treatment of osteoarthritis: meta-analysis of randomised controlled trials. BMJ 329(7461):324

28. Cooper C (2004) Topical NSAIDs in osteoarthritis. BMJ 329:304-305

29. Whitefield M, O'Kane CJA (2002) Comparative efficacy of a proprietary topical ibuprofen gel and oral ibuprofen in acute soft tissue injuries: a randomized, double-blind study. J Clin Pharm Ther 27:409-417 